\title{
The effect of pneumoperitoneum on optic nerve sheath diameter in paediatric patients undergoing laparoscopic appendectomy operation
}

\author{
Monitoring, ultrasound, Brain, intracranial pressure, Anaesthesia, paediatric \\ F. G. Sasal ${ }^{1}$, A. O. Bermede ${ }^{1}$, M. Ozcelik ${ }^{1}$, N. Alkis ${ }^{1}$ \\ ${ }^{1}$ M.D. Ankara University - Ankara (Turkey)
}

Background and Goal of Study: Variations in optic nerve sheath diameter (ONSD) measured by ultrasonography may be an indirect marker of intracranial pressure (ICP) alterations due to increased intraabdominal pressure. The primary aim of this study is to observe the effect of pneumoperitoneum on ONSD measured by ultrasonography, where the secondary goal is to investigate the changes of ONSD caused by perioperative body position in paediatric patients undergoing laparoscopic appendectomy.

Materials and Methods: This study is compromised of the observation over 28 patients (5-12 years in age). After premedication with midazolam $0.5 \mathrm{mg} \mathrm{kg}^{-1} \mathrm{po}$, induction was achieved with propofol $3 \mathrm{mg} \mathrm{kg}{ }^{-1}$, rocuronium $0.6 \mathrm{mg} \mathrm{kg}^{-1}$, remifentanil $0.3-0.5 \mathrm{mcg} \mathrm{kg}^{-1}$ following the routine ASA monitoring. Anaesthesia maintenance was provided by $2-3 \%$ sevoflurane in a mixture of $40 \% \mathrm{O}_{2}-60 \% \quad \mathrm{~N}_{2} \mathrm{O}$. Intraabdominal pressure was maintained as $12 \mathrm{mmHg}$ during pneumoperitoneum. Both left and right ONSD measurements were performed as a transverse diameter of the sheath on $3 \mathrm{~mm}$ far from the exit of the optic nerve with the linear probe of 7-12 $\mathrm{MHz}$ frequency. The values were recorded as follows: $3 \mathrm{~min}$ after induction $\left(t_{0}\right), 5$ min after insufflation $\left(t_{1}\right), 5$ min after trendelenburg and 15 degrees to the left tilted position $\left(t_{2}\right), 15$ min after insufflation $\left(t_{3}\right), 30$ min after insufflation $\left(t_{4}\right)$ and 5 min after desufflation $\left(t_{5}\right)$. For statistical analysis, one way ANOVA, Paired t-test and Wilcoxon tests were applied.

Results and Discussion: ONSD was determined as $t_{0}: 5,12 \pm$ $0,49 \mathrm{~mm}, \mathrm{t}_{1}: 5,41 \pm 0,49 \mathrm{~mm}, \mathrm{t}_{2}: 5,63 \pm 0,58 \mathrm{~mm}$ on the right and $\mathrm{t}_{0}: 5,12 \pm 0,46 \mathrm{~mm}, \mathrm{t}_{1}: 5,42 \pm 0,49 \mathrm{~mm}, \mathrm{t}_{2}: 5,58 \pm 0,46 \mathrm{~mm}$ on the left side.

Table 1: ONSD changes during operation
There was no difference between $t_{0}$ and $t_{5}\left(t_{0}: 5,12 \pm 0,49 \mathrm{~mm}\right.$, $t_{5}: 5,28 \pm 0,53 \mathrm{~mm}$ ) on the right side. However, there was a statistically significant difference between $t_{0}$ and $t_{5}\left(t_{0}: 5,12 \pm\right.$ $\left.0,46 \mathrm{~mm}, t_{5}: 5,30 \pm 0,48 \mathrm{~mm}\right)$ on the left side. There are numerous studies showing that pneumoperitoneum increases the ONSD (1). However, the effect of the body position on ONSD is controversial $(2,3)$. The present study revealed that pneumoperitoneum and also body position changes might affect ONSD. Many studies use the measurement of one eye or the average of the both for ONSD measurement. We measured two eyes separately and observed differences. We argue that the body position has an effect on the left eye's inability to return to its initial value.

Conclusion(s): ONSD might be affected both by increased intraabdominal pressure and patient position, especially Trendelenburg and side tilt. Therefore, USG might be an outstanding method of monitoring the changes of ONSD during laparoscopic procedures in paediatric patients.

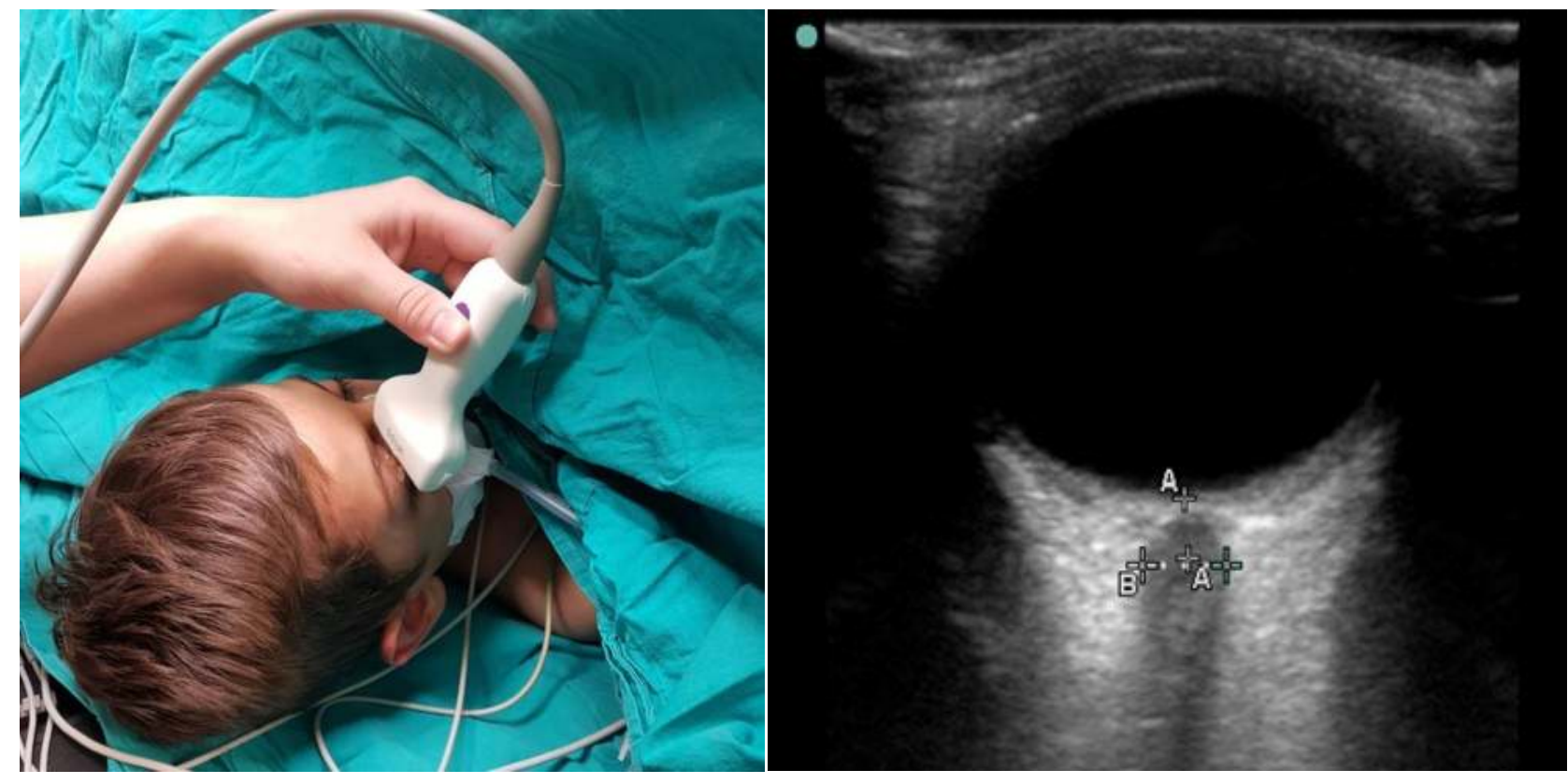

\begin{tabular}{l|l|l|l|l|l|l|} 
& $\begin{array}{l}5 \text { min after inducton } \\
\left(\mathrm{t}_{0}\right) \mathrm{N}: 28\end{array}$ & $\begin{array}{l}3 \mathrm{~min} \text { after } \\
\text { insufflation } \\
\left(\mathrm{t}_{1}\right) \mathrm{N}: 28\end{array}$ & $\begin{array}{l}5 \text { min after position } \\
\text { changes } \\
\left(\mathrm{t}_{2}\right) \mathrm{N}: 28\end{array}$ & $\begin{array}{l}15 \text { min after } \\
\text { insufflation } \\
\left(\mathrm{t}_{3}\right) \mathrm{N}: 22\end{array}$ & $\begin{array}{l}\mathbf{3 0} \text { min after } \\
\text { insufflation } \\
\left(\mathrm{t}_{4}\right) \mathrm{N}: 14\end{array}$ \\
\hline $\begin{array}{l}\text { ONSD- right } \\
(\mathrm{mm})\end{array}$ & $5,12 \pm 0,49^{*}$ & $5,41 \pm 0,49 *$ & $5,63 \pm 0,58$ & $5,72 \pm 0,36$ & $5,57 \pm 0,43$ \\
\hline $\begin{array}{l}\text { ONSD- left } \\
(\mathrm{mm})\end{array}$ & $5,12 \pm 0,46 * *$ & $5,42 \pm 0,49 * *$ & $5,58 \pm 0,46$ & $5,73 \pm 0,36$ & $5,62 \pm 0,38$ & $5,30 \pm 0,48 * * * *$ \\
\hline
\end{tabular}

$*_{\%} 95 \mathrm{Cl}_{0}$ and $\mathrm{t}_{1}$ for: $\mathrm{p}<0.001, \mathrm{t}_{1}$ and $\mathrm{t}_{2}$ for $\mathrm{p}=0.001$

$* * \% 95 \mathrm{Cl}_{0}$ and $t_{1}$ for $p<0.001, t_{1}$ and $t_{2}$ for $p=0.003$

$* * * \% 95 \mathrm{Cl} \mathrm{t}_{0}$ and $\mathrm{t}_{5}$ for $\mathrm{p}=0.27$

$* * * * \% 95 \mathrm{Cl} \mathrm{t}_{0}$ and $\mathrm{t}_{5}$ for $\mathrm{p}=0.019$

1- Min JY, Lee JR, Oh JT, Kim MS, Jun EK, An J. Ultrasonographic assessment of optic nerve sheath diameter during pediatric laparoscopy. Ultrasound Med Biol 2015;41:1241-6. 2- Kim SH, Kim HJ, Jung KT. Position does not affect the optic nerve sheath diameter during laparoscopy. Korean Journal of Anesthesiology. 2015;68(4):358-363.

3- Chin J-H, Seo H, Lee E-H, et al. Sonographic optic nerve sheath diameter as a surrogate measure for intracranial pressure in anesthetized patients in the Trendelenburg position. BMC Anesthesiology. 2015;15:43. 